Open Access

\title{
Long-term functional outcome and quality of life following rotationplasty for treatment of malignant tumors
}

Guntmar Gradl', Lukas K. Postl ${ }^{1,2}$, Ulrich Lenze ${ }^{1}$, Josef Stolberg-Stolberg ${ }^{1}$, Florian Pohlig ${ }^{1}$, Hans Rechl1, Markus Schmitt-Sody ${ }^{3}$, Ruediger von Eisenhart-Rothe ${ }^{1^{*}}$ and Chlodwig Kirchhoff, ${ }^{1,2}$

\begin{abstract}
Background: Malignant bone tumors of the lower extremity are more frequently found in children and adolescents than in adults. Modern treatment regimens led to high limb salvage rates and offer the choice between endoprosthetic replacement and rotationplasty in many cases. Rotationplasty has proven to be an effective, highly functional option in short- and mid-term studies. Aim of this study was to assess long-term results regarding quality of life and functionality after rotationplasty and to compare the obtained results to a representative healthy German sample cohort.
\end{abstract}

Methods: In total 12 patients who underwent rotationplasty between 1991 and 2001 were enrolled in this study. After physical examination, they were evaluated regarding health related quality of life, functional outcome and psychosocial status. While quality of life was mainly assessed using the SF-36 (The Short Form (36) Health Survey v2), functional outcome was measured using the musculoskeletal tumor society score (MSTS) as well as the Tegner activity level scale.

Results: Average age at the time of surgery was $19 \pm 10$ year. and $32 \pm 11$ year. at the time of follow up. Mean follow-up was $14 \pm 9$ years. The SF-36 scores accounted for $80.4 \pm 15.7$ regarding physical functioning, for $78.1 \pm 24.1$ regarding the physical role functioning, for $74.1 \pm 17.6$ regarding bodily pain and for $71.8 \pm 26.1$ regarding general health. SF-36 score for vitality was $75.0 \pm 12.8$, for social functioning $98.9 \pm 3.6,88.2 \pm 23.9$ for emotional role functioning and $89.6 \pm 10.1$ for the mental health. Comparison to a representative German sample cohort revealed significantly higher patient's scores for vitality, social functioning and mental health $(p<0.05)$. The overall MSTS resulted in an average of $64 \pm 12 \%$ and the Tegner activity level scale accounted for $4.1 \pm 0.6$ pts.

Conclusions: The presented long-term results indicate that rotationplasty provides a high quality of life. Patients are satisfied with a good functional outcome regarding activities of daily life and even sports.

Keywords: Rotationplasty, Bone tumor, Sarcoma, Quality of life, Function, Long-term

\footnotetext{
* Correspondence: Eisenhart@tum.de

'Department of Orthopedics and Sports Orthopedics, Klinikum rechts der Isar, Technische Universitaet Muenchen, Ismaningerstrasse 22, 81675 Munich, Germany

Full list of author information is available at the end of the article
} 


\section{Background}

Sarcomas account for approximately $1 \%$ of all adult cancers [1]. In this context soft tissue sarcomas typically occur in middle aged and older adults [1], whereas malignant bone tumors, i.e., osteosarcoma and Ewing's sarcoma are more frequent in children and adolescents $[2,3]$. Progress in modern treatment regimens including neoadjuvant and adjuvant therapy has markedly improved the overall survival rates over the last decades [4]. Therefore, analysis of long-term outcome after malignant bone tumor therapy gains more and more importance. Moreover only a minor percentage of patients require primary amputation due to the efforts of limb preserving surgical procedures [3, 5-9]. Nowadays endoprosthetic knee replacement is associated with good functional, cosmetic and psychological outcomes, resulting in significantly better walking efficiency and musculoskeletal tumor society scores (MSTS) in comparison to major amputation or arthrodesis [10-12].

In contrast rotationplasty has been proven to be associated with equivalent functional outcomes, but better quality of life as well as less limitations during daily activities and less pain in the short- and mid-term outcome [13-17]. However, especially the cosmetic result is not as appealing as for traditional limb sparing alternatives. In this context only a small number of studies investigated the health-related quality of life (HRQL) and the long-term outcome after rotationplasty for the treatment of malignant bone tumors [18-20]. Therefore the aim of this study was to assess long-term results following rotationplasty with regard to HRQL, functional performance and psychosocial aspects and to compare theses results to a representative healthy German sample cohort [21].

\section{Methods}

Ethical approval for this project was granted by the local ethics committee (Klinikum rechts der Isar, Medical Faculty, reference no. 4092/11). Written informed consent was obtained from each patient prior to enrolment in the study.

\section{Patients}

All patients who had been treated by rotationplasty for malignant bone or soft tissue tumors of the lower extremity at our academic musculoskeletal tumor center (MSTC) between May 1991 and June 2001 were identified from our database.

\section{Questionnaires}

Before assessing the questionnaires all patients were clinically examined by an expert orthopedic surgeon (GG).

The Short Form Health Survey (SF-36v2) was used for the assessment of HRQL [22]. The SF-36v2 is a questionnaire assessing the individual health of patients as well as disease-related distress by eight scaled dimensions. Each scale ranges from zero (poor) to 100 (excellent). The eight dimensions are vitality, physical functioning, bodily pain, general health perceptions, physical role functioning, emotional role functioning, social role functioning and mental health [22].

The functional outcome was evaluated using the musculoskeletal tumor society score (MSTS) [23]. The MSTS evaluates the functional outcome of tumor patients after completed therapy. It consists of six components for the lower limb: pain, function, emotional acceptance, need for walking aids, walking and gait. The maximum (best) score for each item is 5 (range from $0-5$ ). The values of each of the six components are added and divided by the maximum possible number of pts. (30). The percentage value is obtained by multiplying the calculated point value by 100 .

In addition the Tegner activity level scale [24] was assessed. The Tegner activity level scale ranges from zero to ten. While an activity level of zero means sick leave or disability because of knee problems, a level of five means that the patients are able to perform heavy labor and recreational sports twice a week and a level of ten means that the person pertains to the national elite in competitive sports [25].

\section{Statistics}

Statistical analysis was performed using Sigma Stat 3.1 software (Systat Inc, Chicago, Illinois, USA. Unless otherwise stated the data is given in means (arithmetic mean) \pm standard deviation (SD). Welch's $t$-test (twosample unpooled $t$-test for unequal variances) was calculated for comparing SF-36v2 results of our patients to a representative healthy German sample cohort [21] using QuickCalcs software (GraphPad Software Inc, La Jolla, California, USA). A p-value $<0.05$ was considered statistically significant.

\section{Results \\ Patients}

Overall 23 patients underwent rotationplasty between 1991 and 2001. Nine patients deceased due to the malignant disease, two patients were lost for follow-up. Summarizing, twelve patients ( 7 male, 5 female) with a median age at the time of treatment of $19 \pm 10$ year. and a median age of $33 \pm 11$ year. at follow up were enrolled. The mean follow-up was $14 \pm 9$ years. The diagnoses consisted of osteosarcoma $(n=9)$, chondrosarcoma $(n=2)$ and one synovial sarcoma (for patient's details see Table 1). Patients, suffering from osteosarcoma were treated according to the Cooperative Osteosarcoma Study Group (COSS) protocol and received multidrug chemotherapy before and after surgery [26]. The patient suffering from 
Table 1 Overview of patient characteristics including diagnosis, treatment, complications and postoperative social status $(n=12)$

\begin{tabular}{|c|c|}
\hline \multicolumn{2}{|l|}{ Gender } \\
\hline male & 7 \\
\hline female & 5 \\
\hline \multicolumn{2}{|l|}{ Age at surgery (yrs of age) } \\
\hline Mean & $19 \pm 10$ \\
\hline Median (Range) & $18(4-46)$ \\
\hline \multicolumn{2}{|l|}{ Follow up (yrs) } \\
\hline Mean & $14 \pm 3$ \\
\hline Median (Range) & $15(8-18)$ \\
\hline \multicolumn{2}{|l|}{ Diagnosis } \\
\hline Osteosarcoma & 9 \\
\hline Chondrosarcoma & 2 \\
\hline Synovial sarcoma & 1 \\
\hline \multicolumn{2}{|l|}{ Anatomic Site } \\
\hline Distal Femur & 9 \\
\hline Proximal Femur & 3 \\
\hline \multicolumn{2}{|l|}{ Treatment } \\
\hline Borggreve Rotationplasty & 10 \\
\hline Winkelmann Rotationplasty & 2 \\
\hline \multicolumn{2}{|l|}{ Winkelmann Classification } \\
\hline Al & 8 \\
\hline B I & 1 \\
\hline B II & 2 \\
\hline B Illa & 1 \\
\hline \multicolumn{2}{|l|}{ Complications } \\
\hline Implant loosening & 1 \\
\hline Impingement & 1 \\
\hline Achilles tendon tear & 1 \\
\hline \multicolumn{2}{|l|}{ Marital state } \\
\hline Married & 5 \\
\hline Divorced & - \\
\hline Never Married & 7 \\
\hline Living together with Partner & 1 \\
\hline Living separated from Partner & 1 \\
\hline Single living with parents & 1 \\
\hline Single living alone & 4 \\
\hline \multicolumn{2}{|l|}{ Education } \\
\hline Less than compulsory & 1 \\
\hline Compulsory & 8 \\
\hline Postcompulsory & 3 \\
\hline University level & - \\
\hline \multicolumn{2}{|l|}{ Employment state } \\
\hline Full-time job & 7 \\
\hline Part-time job & 1 \\
\hline Student & 3 \\
\hline Illness retirement & 1 \\
\hline
\end{tabular}

synovial sarcoma underwent additional neoadjuvant and adjuvant chemotherapy following the consensus of our interdisciplinary tumor board.

Referring to the classification according to Winkelmann et al. in eight cases an AI type, in one case a BI, in two cases a BII and in another case a BIIIa-rotationplasty was performed [27].

\section{Complications}

One patient underwent one revision surgery once due to prolonged healing of the osteotomy and implant loosening. Another patient had to be treated for impingement of the Borggreve joint. One patient needed ten revision procedures due to traumatic Achilles tendon tear with consecutive postoperative wound infection. There were no further major complications recorded.

\section{Health-Related Quality of Life (HRQL)}

Analysis of the psychosocial outcome, measured by the SFv2-36 revealed for the subcategory physical health $80.4 \pm 15.7$ for the dimension physical functioning, $78.1 \pm 24.1$ for physical role functioning, $74.1 \pm 17.6$ for bodily pain and $71.8 \pm 26.1$ for general health.

Scores for the subcategory mental health state were $75.0 \pm 12.8$ for vitality, $98.9 \pm 3.6$ for social functioning, $88.2 \pm 23.9$ for emotional role functioning and $89.6 \pm 10.1$ for mental health (for details see Table 2). The comparison of the presented results to a representative healthy German sample cohort (mean age $49 \pm 18$ years) revealed significantly higher scores for the patients regarding the dimensions vitality $(p=0.0243)$, social functioning $(p=$ $0.0001)$ and mental health $(p=0.0001)$ [21].

\section{Functional outcomes}

The overall MSTS resulted in an average of $64 \pm 12 \%$ with $63 \pm 15.4 \%$ for male and $66 \pm 5.7 \%$ for female patients. Analysis of the subcategories revealed $4 \pm 0.8$ pts. for pain, $3.3 \pm 1.2$ for function, $3.3 \pm 1$ for emotional acceptance, $2.8 \pm 0.6$ for walking supports, $3.3 \pm 0.4$ for walking distance and $2.6 \pm 1$ for gait (see Fig. 1). The Tegner activity level scale accounted for $4.1 \pm 0.6$ pts (see Fig. 2).

Ten patients reported no or occasional pain, two complained about moderate daily pain. Only five patients reported limitations during recreational activities and one patient was limited during daily activities. The walking distance of nine patients was greater than 6 blocks and within the range of 4-6 blocks for the remaining three patients. Five patients had no and seven patients some difficulties while walking on uneven terrain. In seven patients the gait pattern was not or slightly and in five patients obviously altered.

Ten patients reported, having little problems in participating in sports, one of the patients is a national 
Table 2 Results of the SFv2-36 questionnaire assessing function and mental health of patients after rotationplasty of our series and a representative German sample [21]

\begin{tabular}{lllllllll}
\hline Subjects & $\begin{array}{l}\text { Physical } \\
\text { functioning }\end{array}$ & $\begin{array}{l}\text { Physical } \\
\text { Role }\end{array}$ & Bodily pain & General health & Vitality & Social role & Emotional role & Mental health \\
\hline Rotationplasty $(n=12)$ & $80.4 \pm 15.7$ & $78.1 \pm 24.1$ & $74.1 \pm 17.6$ & $71.8 \pm 26.7$ & $75.0 \pm 12.8$ & $98.9 \pm 3.6$ & $88.2 \pm 23.9$ & $89.6 \pm 10.1$ \\
$\begin{array}{l}\text { Representative healthy } \\
\text { German sample cohort } \\
(n=2043)[21]\end{array}$ & $87.2 \pm 20.4$ & $81.8 \pm 23.1$ & $79.3 \pm 25.3$ & $64.4 \pm 15.2$ & $65.3 \pm 18.3$ & $87.5 \pm 19.3$ & $84.7 \pm 22.7$ & $72.3 \pm 17.2$ \\
$p$ & 0.1635 & 0.6064 & 0.3309 & 0.3581 & 0.0243 & 0.0001 & 0.6229 & 0.0001 \\
\hline
\end{tabular}

champion in handicapped swimming and the one patient with Achilles tendon tear performs no sports at all.

Regarding range of motion of the neo-knee flexion and extension corresponded to the levels of the contralateral ankle joint with a mild restriction $\left(10^{\circ}\right)$ in eleven patients and a moderate restriction $15^{\circ}$ in one patient. In- and eversion was normal in all patients. The joint was regarded stable (varus/valgus stability) in all patients.

Four patients even had children following the rotationplasty. Only one patient is currently not able to work because his work as storekeeper requires carrying heavy loads. All but one patient, who was not sure, would choose a rotationplasty as treatment option again, facing the choice between amputation, endoprosthetic knee replacement or rotationplasty.

\section{Discussion}

The objective of this retrospective study was to evaluate the long-term outcome as well as health-related quality of life (HRQL) in patients who underwent rotationplasty for treatment of a malignant bone or soft tissue tumour. At a mean follow-up of $14 \pm 9$ years. HRQL, assessed by the Short Form Health Survey (SF-36v2) revealed good to excellent scores for each dimension. Interestingly the scores for vitality, social functioning and mental health were significantly higher compared to a representative healthy German sample cohort [21]. Functional long- term outcome measured by the musculoskeletal tumor society score (MSTS) and the Tegner activity level scale also revealed a good functional outcome with $64 \pm 12 \%$ and $4.1 \pm 0.6$ pts., respectively. All but one patient, who was not sure, would choose rotationplasty as therapy option again.

Rotationplasty implies significant shortening of the leg and rotation of the foot $180^{\circ}$ around the vertical axis [28]. Therefore the former ankle adopts the role of a neo-knee with ankle dorsiflexion simulating knee flexion $[29,30]$. Although the procedure allows for a function more akin to transtibial amputation due to retention of voluntary control of motion at the 'knee' level the significant cosmetic alteration implies potential future socio-psychiatric issues that might impact health and HRQL [31]. However, in our cohort we found good to excellent results regarding the subcategory physical health as well as the mental health state. These findings are in line with the work of Veenstra et al. who reported that the subdivisions daily emotional interaction, emotional support in problematic situations and social companionship are comparable to a healthy control group [32]. Consistent with previous studies, the majority of our patients presented well-adjusted in terms of social integration [33]. Though Veenstra et al. also reported almost half of the patients had negative effects of the surgery on initiating social or intimate contact, body

\section{MSTS-Score}

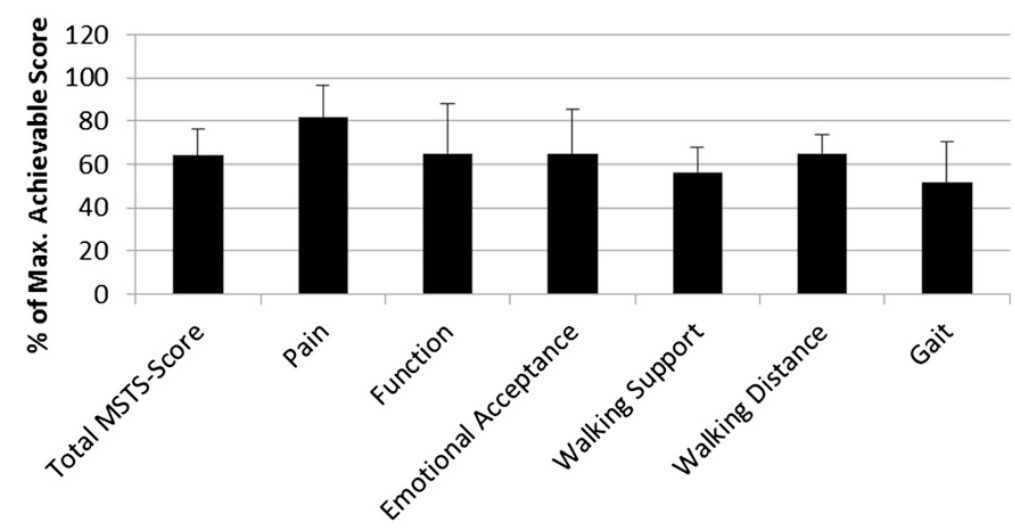

Fig. 1 Percentage of maximum MSTS-Score and sub-scores of patients after rotationplasty 


\section{Overview Long Term Outcomes}

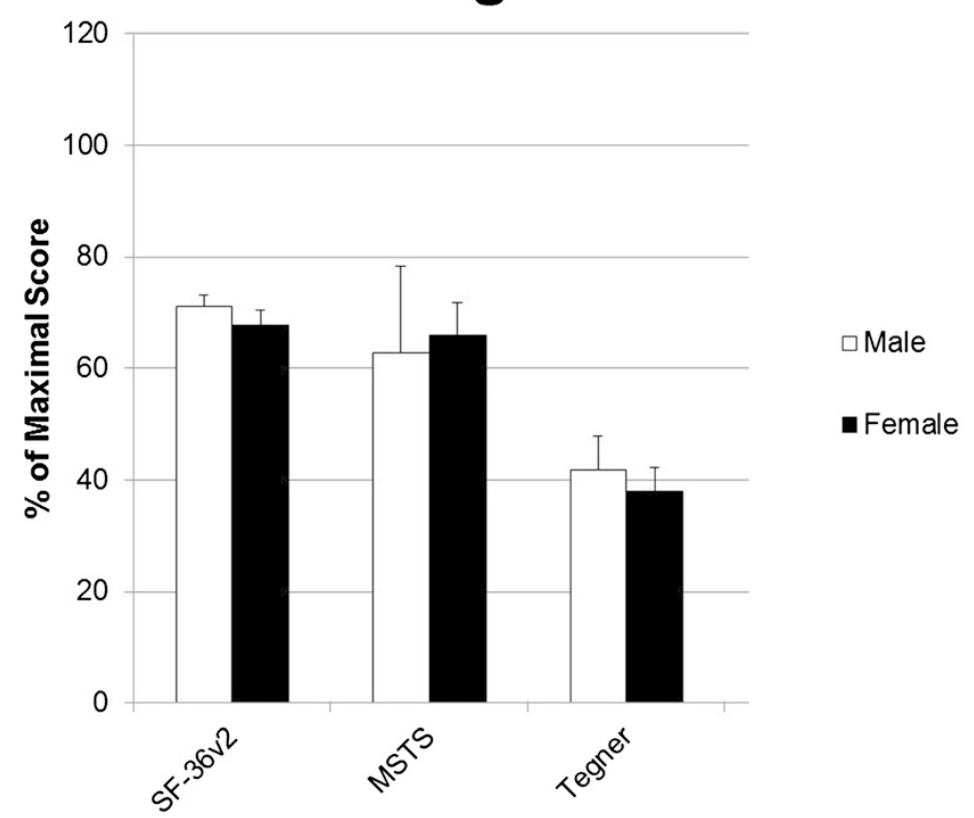

Fig. 2 Overview of percentages of maximum score of the assessed questionnaires with standard deviations. White bars for male and black bars for female patients

image [32]. In this context patients after treatment with mega-prosthesis seem to be more satisfied [32, 34]. At least patients in our study had children following the rotationplasty in four cases.

One of our unexpected findings was, that scores for vitality, social functioning and mental health were significantly higher in our series in comparison to a representative German sample [21]. At first glance this finding is hard to understand. However, in comparing our findings to the results of long-term survivors of other malignancies, our study might underline the concept of posttraumatic growth $[35,36]$. In this context Sears et al. reported that $83 \%$ of breast cancer patients felt at least one benefit in their disease [36]. These women mentioned that following cancer diagnosis and consecutive therapy they live now more intensively and consciously. Furthermore, women evaluated the social support they received during the illness as a positive aspect. This seems to be an important aspect of coping with the illness, as it has been demonstrated that social support is a significant predictor for a better long-term quality of life in breast cancer patients [36].

Of course functional outcome has a significant impact of on HRQL, as a significant reduction of HRQL was reported in patients with a MSTS <50 \% [37]. In our study only one patient with an MSTS of $47 \%$ was found to be below the $50 \%$ threshold. This patient had sustained an Achilles tendon tear with several consecutive revision surgeries. Our other patients presented with an average MSTS of $64 \pm 12.41 \%$. This is in line with the literature reporting MSTS between 63 and 80 \% following rotationplasty $[38,39]$. Comparative studies showed significantly higher MSTS-scores after endoprosthetic knee replacement than after rotationplasty [39]. Tunn et al. report MSTS-scores of 77 to $87 \%$ after endoprosthetic limb salvage therapy of primary bone tumors in proximal tibia and distal femur, respectively [40]. However, there are also higher rates of postoperative complications reported following endoprosthetic knee replacement. In this context Warrener et al. noted complications in $42 \%$ of patients following arthroplasty and only in $25 \%$ following rotationplasty [39]. Aseptic loosening and mechanical failure are the most common complications [41]. Additionally, rising numbers of periprosthetic infections with multidrug resistant bacteria cause increasing concern [42]. Our patients were highly satisfied with a stable new joint offering high functionality for daily activities. The nature of the operation obviously causes difficulties with complex movements such as heel walking, jumping or walking on uneven terrain [30, 31]. However, most of our patients reported little problems in participating in sports, one of the patients is even a national champion in handicapped swimming. With an average Tegner activity level scale of 4.1 our patients felt able to perform moderately heavy work and some recreational sports. In comparison a healthy cohort achieved nearly two grades more (5.7) and was therefore able to perform heavy labor, competitive sports and recreational sports several times a week. This 
seems to be in line with the work of Hillmann et al., who reported that $85 \%$ of the patients following rotationplasty were actively participating in "high-level" sports [43].

\section{Limitations}

Several strengths and limitations of the present study have to be considered. On the one hand we focus on an extremely rare surgical entity and enrolled at least 12 patients. The average follow-up of $14 \pm 9$ years. is, according to the best of our knowledge one of the longest, reported in literature. Furthermore all enrolled patients were clinically seen by a doctor and fulfilled the questionnaires under advice. However, due to the rarity of rotationplasty the small number of patients limits this retrospective study. Moreover, a significant number of patients had deceased due to the disease. This might create a potential bias. Additionally the age at the time of surgery as well as the underlying diagnosis was quite heterogeneous.

\section{Conclusions}

Since limb amputation is associated with lower functional outcome, lower health related quality of life and no positive effects on survival compared to both rotationplasty and endoprosthetic reconstruction, alternative treatment options should be considered first [44-46]. Although recent studies show that modern endoprosthetic reconstructions show equal or even better functional outcomes than rotationplasty, endoprostheses bare the risk of high complication rates [38-42]. The presented long-term results indicate that rotationplasty provides a high HRQL and that patients are satisfied with a good functional outcome regarding activities of daily life. In terms of vitality, social function and mental health our study group showed even significant higher scores compared to a representative German sample in the SF-36v2 survey. In this regard we consider our work to be of distinct relevance regarding the discussion of surgical treatment plans for patients suffering from malignant tumors of the lower thigh and the choice whether to perform a rotationplasty or a endoprosthetic reconstruction.

\section{Competing interests}

The authors declare that they have no competing interests.

\section{Authors' contributions}

LKP, UL, JSS GG, FP, CK contributed to study design, data collection and analysis. CK, HR, MSS and RVER contributed to study design, funding and manuscript review. CK wrote the final manuscript. All authors read and approved the final manuscript.

\section{Author details}

${ }^{1}$ Department of Orthopedics and Sports Orthopedics, Klinikum rechts der Isar, Technische Universitaet Muenchen, Ismaningerstrasse 22, 81675 Munich, Germany. ${ }^{2}$ Department of Trauma Surgery, Klinikum rechts der Isar, Technische Universitaet Muenchen, Munich, Germany. ${ }^{3}$ Department of
Orthopedics, Klinikum der Universitaet Muenchen, Ludwig-Maximilians-Universitaet, Munich, Germany.

Received: 4 September 2014 Accepted: 16 September 2015 Published online: 24 September 2015

\section{References}

1. Grimer R, Judson I, Peake D, Seddon B. Guidelines for the management of soft tissue sarcomas. Sarcoma. 2010;2010:506182.

2. von Eisenhart-Rothe R, Toepfer A, Salzmann M, Schauwecker J, Gollwitzer H, Rechl H. [Primary malignant bone tumors]. Orthopade. 2011;40(12):1121-42.

3. Andreou D, Hardes J, Gosheger G, Henrichs MP, Nottrott M, Streitburger A. [Interdisciplinary diagnostic and treatment of bone sarcomas of the extremities and trunk]. Handchirurgie, Mikrochirurgie, plastische Chirurgie : Organ der Deutschsprachigen Arbeitsgemeinschaft fur Handchirurgie : Organ der Deutschsprachigen Arbeitsgemeinschaft fur Mikrochirurgie der Peripheren Nerven und Gefasse. 2015:47(2):90-9.

4. Wilkins RM, Cullen JW, Odom L, Jamroz BA, Cullen PM, Fink K, et al. Superior survival in treatment of primary nonmetastatic pediatric osteosarcoma of the extremity. Ann Surg Oncol. 2003;10(5):498-507.

5. Papagelopoulos PJ, Mavrogenis AF, Mastorakos DP, Patapis P, Soucacos PN. Current concepts for management of soft tissue sarcomas of the extremities. J Surg Orthop Adv. 2008;17(3):204-15.

6. Bacci G, Ferrari S, Bertoni F, Ruggieri P, Picci P, Longhi A, et al. Long-term outcome for patients with nonmetastatic osteosarcoma of the extremity treated at the istituto ortopedico rizzoli according to the istituto ortopedico rizzoli/osteosarcoma-2 protocol: an updated report. J Clin Oncol Off J Am Soc Clin Oncol. 2000;18(24):4016-27.

7. Ferrari $S$, Smeland $S$, Mercuri $M$, Bertoni $F$, Longhi A, Ruggieri $P$, et al. Neoadjuvant chemotherapy with high-dose Ifosfamide, high-dose methotrexate, cisplatin, and doxorubicin for patients with localized osteosarcoma of the extremity: a joint study by the Italian and Scandinavian Sarcoma Groups. J Clin Oncol. 2005:23(34):8845-52.

8. Grimer RJ. Surgical options for children with osteosarcoma. Lancet Oncol. 2005;6(2):85-92.

9. Ayerza MA, Farfalli GL, Aponte-Tinao L, Muscolo DL. Does increased rate of limb-sparing surgery affect survival in osteosarcoma? Clin Orthop Relat Res. 2010;468(11):2854-9.

10. Rougraff BT, Simon MA, Kneisl JS, Greenberg DB, Mankin HJ. Limb salvage compared with amputation for osteosarcoma of the distal end of the femur. A long-term oncological, functional, and quality-of-life study. J Bone Joint Surg Am Vol. 1994;76(5):649-56.

11. Mizuno N, Aoyama T, Nakajima A, Kasahara T, Takami K. Functional evaluation by gait analysis of various ankle-foot assemblies used by belowknee amputees. Prosthetics Orthot Int. 1992;16(3):174-82.

12. Otis JC, Lane JM, Kroll MA. Energy cost during gait in osteosarcoma patients after resection and knee replacement and after above-the-knee amputation. J Bone Joint Surg Am Vol. 1985;67(4):606-11

13. Cammisa Jr FP, Glasser DB, Otis JC, Kroll MA, Lane JM, Healey JH. The Van Nes tibial rotationplasty. A functionally viable reconstructive procedure in children who have a tumor of the distal end of the femur. J Bone Joint Surg Am Vol. 1990;72(10):1541-7.

14. Hillmann A, Hoffmann C, Gosheger G, Krakau H, Winkelmann W. Malignant tumor of the distal part of the femur or the proximal part of the tibia: endoprosthetic replacement or rotationplasty. Functional outcome and quality-of-life measurements. J Bone Joint Surg Am. 1999;81(4):462-8.

15. Hopyan S, Tan JW, Graham HK, Torode IP. Function and upright time following limb salvage, amputation, and rotationplasty for pediatric sarcoma of bone. J Pediatr Orthop. 2006;26(3):405-8.

16. Jacobs PA. Limb salvage and rotationplasty for osteosarcoma in children. Clin Orthop Relat Res. 1984;188:217-22.

17. Kotz R, Salzer M. Rotation-plasty for childhood osteosarcoma of the distal part of the femur. J Bone Joint Surg Am Vol. 1982;64(7):959-69.

18. Health related quality of life in adolescent and young adult survivors of lower extremity bone tumors. Barrera M, Teall T, Barr R, Silva M, Greenberg M. Pediatr Blood Cancer. 2012;58(2):265-73. doi: 10.1002/pbc.23017. Epub 2011 Feb 11.

19. Rotationplasty (Borggreve/Nan Nes and modifications) as an alternative to amputation in failed reconstructions after resection of tumours around the knee joint. Ramseier LE, Dumont CE, Exner GU. Scand J Plast Reconstr Surg Hand Surg. 2008;42(4):199-201. 
20. Hanlon M, Krajbich II. Rotationplasty in skeletally immature patients. Longterm followup results. Clin Orthop Relat Res. 1999:358:75-82.

21. Morfeld M, Bullinger M, Nantke J, Brahler E. The version 2.0 of the SF-36 Health Survey: results of a population-representative study. Soz Praventivmed. 2005;50(5):292-300

22. Ware JE, Jr, Kosinski, M., Bjorner, J. B., Turner-Bowker, D. M., Gandek, B., \& Maruish, M. E.: User's manual for the SF-36v2 $2^{\text {TM }}$ health survey ( 2 nd ed.). Lincoln 2007(RI: QualityMetric Incorporated).

23. Enneking WF, Dunham W, Gebhardt MC, Malawar M, Pritchard DJ. A system for the functional evaluation of reconstructive procedures after surgical treatment of tumors of the musculoskeletal system. Clin Orthop Relat R. 1993;286:241-6.

24. Tegner $Y$, Lysholm J. Rating systems in the evaluation of knee ligament injuries. Clin Orthop Relat Res. 1985;198:43-9.

25. Return to play following $A C L$ reconstruction: survey among experienced arthroscopic surgeons (AGA instructors). Petersen W, Zantop T. Arch Orthop Trauma Surg. 2013;133(7):969-77. doi: 10.1007/s00402-013-1746-1.

26. Bielack $S$, Jurgens $H$, Jundt $G$, Kevric M, Kuhne $T$, Reichardt $P$, et al. Osteosarcoma: the COSS experience. Cancer Treat Res. 2009;152:289-308.

27. Winkelmann WW. Rotationplasty. Orthop Clin N Am. 1996;27(3):503-23.

28. Gebert C, Hardes J, Vieth V, Hillmann A, Winkelmann W, Gosheger G. The effect of rotationplasty on the ankle joint: long-term results. Prosthetics Orthot Int. 2006;30(3):316-23.

29. Bernthal NM, Monument MJ, Randall RL, Jones KB. Rotationplasty: beauty is in the Eye of the beholder. Oper Tech Orthop. 2014;24(2):103-10.

30. Harris JD, Trinh TQ, Scharschmidt TJ, Mayerson JL. Exceptional functional recovery and return to high-impact sports after Van Nes rotationplasty. Orthopedics. 2013;36(1):e126-31.

31. So NF, Andrews KL, Anderson K, Gozola MA, Shives TC, Rose PS, et al. Prosthetic fitting after rotationplasty of the knee. Am J Phys Med Rehabil. 2014;93(4):328-34

32. Veenstra KM, Sprangers MAG, Van der Eyken JW, Taminiau AHM. Quality of life in survivors with a Van Ness-Borggreve rotationplasty after bone tumour resection. J Surg Oncol. 2000;73(4):192-7.

33. Rodl RW, Pohlmann U, Gosheger G, Lindner NJ, Winkelmann W. Rotationplasty - quality of life after 10 years in 22 patients. Acta Orthop Scand. 2002;73(1):85-8.

34. Henderson E, Pepper A, Marulanda G, Millard J, Letson GD. What is the emotional acceptance after limb salvage with an expandable prosthesis? Clin Orthop Relat Res. 2010;468(11):2933-8.

35. Jiao-Mei X, Wen G, Feng-Lin C. Quality of life among breast cancer survivors 2 years after diagnosis: the relationship with adverse childhood events and posttraumatic growth. Cancer Nurs. 2015 [Epub ahead of print].

36. Sears SR, Stanton AL, Danoff-Burg S. The yellow brick road and the emerald city: benefit finding, positive reappraisal coping and posttraumatic growth in women with early-stage breast cancer. Health Psychol. 2003;22(5):487-97.

37. Kreshak JL, Fabbri N, Manfrini M, Gebhardt M, Mercuri M. Rotationplasty for sarcomas of the distal femur: long-term survival, function and quality of life. J Bone Joint Surgery Br Vol. 2012;94-B(143).

38. Shehadeh A, Noveau J, Malawer M, Henshaw R. Late complications and survival of endoprosthetic reconstruction after resection of bone tumors. Clin Orthop Relat Res. 2010;468(11):2885-95.

39. Warrener T, El-Dalil P, Abudu A, MDe S. A comparative study of complications and functional outcomes of endoprosthetic replacement and rotationplasty in childhood. J Bone Joint Surg Br Vol. 2011;93-B:75.

40. Tunn PU, Pomraenke D, Goerling U, Hohenberger P. Functional outcome after endoprosthetic limb-salvage therapy of primary bone tumours - a comparative analysis using the MSTS score, the TESS and the RNL index. Int Orthop. 2008;32(5):619-25.

41. Henderson ER, Pepper AM, Marulanda G, Binitie OT, Cheong D, Letson GD. Outcome of lower-limb preservation with an expandable endoprosthesis after bone tumor resection in children. J Bone Joint Surgery Am Vol. 2012;94A(6):537-47.

42. Ascherl R. Infektionsmanagement bei Megaimplantaten. Orthopade. 2010;39(10):980-93.

43. Hillmann A, Weist R, Fromme A, Volker K, Rosenbaum D. Sports activities and endurance capacity of bone tumor patients after rotationplasty. Arch Phys Med Rehabil. 2007;88(7):885-90.

44. Kreshak JL, Fabbri N, Manfrini M, Gebhardt M, Mercuri M. Rotationplasty for sarcomas of the distal femur: long-term survival, function and quality of life. J Bone Joint Surg Br Vol. 2012;94-B(SUPP XXXVIII):143.
45. Aksnes LH, Bauer HCF, Jebsen NL, Folleras G, Allert C, Haugen GS, et al. Limb-sparing surgery preserves more function than amputation - a Scandinavian sarcoma group study of 118 patients. J Bone Joint Surg Br Vol. 2008;90B(6):786-94.

46. DiCaprio MR, Friedlaender GE. Malignant bone tumors: limb sparing versus amputation. J Am Acad Orthop Surg. 2003;11(1):25-37.

\section{Submit your next manuscript to BioMed Central and take full advantage of:}

- Convenient online submission

- Thorough peer review

- No space constraints or color figure charges

- Immediate publication on acceptance

- Inclusion in PubMed, CAS, Scopus and Google Scholar

- Research which is freely available for redistribution 